\title{
Predicting Refractive Index of Fluoride Containing Glasses For Aesthetic Dental Restorations
}

\begin{abstract}
Objective Dental restoration aesthetics, particularly the translucency of modern dental restorative filling materials depends on the Refractive Index $(\mathrm{RI})$ match between the different components in the material. In the case of dental composites (DC), the RI of the polymer must match the RI of the filler otherwise the material is optically opaque and has limited depth of cure. In the case of glass ionomer cements (GICs), the RI of the ion-leachable glass must match the $\mathrm{RI}$ of the polysalts to engineer a smart material with a tooth-like appearance. The RI of oxide glasses can be calculated by means of Appen factors. However, no Appen factors are available for the fluoride components in dental glasses. Therefore, the objective of this study is to empirically derive composition-specific Appen factors for the metal fluorides in complex multicomponent glasses for use in dentistry. Methods Two series of bioactive glasses and two series of ionomer-type glasses were produced for this study. Refractive indices of all glasses were then measured by the Becke Line technique. Thereafter, composition-specific factors for the metal fluorides were derived. Results It was found that increasing metal fluoride content reduces the RI of multicomponent dental glasses linearly. A series-specific Appen factors for the metal fluorides were successfully derived and allow RI calculation to within 0.005. Significance This paper proposes a modified Appen Model with composition-specific Appen factors for the metal fluorides for the development of dental restoratives with enhanced aesthetics and improved depth of cure of dental composites.
\end{abstract}

Key Words: aesthetics; glass ionomer cement; dental composite; fluoride; refractive index; translucency 


\subsection{Introduction}

The aesthetics, particularly the translucency is an important feature of dental restorations. In order to obtain a translucent glass ionomer cement (GIC) or a dental composite (DC) it is essential to match the refractive index of the glass to the polymer or the polysalt cement matrix to avoid light scattering at the interfaces. Light scattering at the interfaces results in an opaque material. In DCs, light scattering because of a RI mismatch between the resin and the glass filler causes light attenuation and strongly influences the depth of cure of the composite material [1]. Furthermore, in photoactive resin based composites RI mismatch between the resin and the filler increases light scattering, however the $\mathrm{RI}$ of the resin changes dynamically during the curing process [2]. This can either increase or decrease light scattering depending on the refractive index match, i.e. if the $\mathrm{Rl}$ of the filler matches the $\mathrm{RI}$ of the uncured resin, then light scattering will increase as the material polymerizes and if the RI of the resin is lower, then as the material polymerizes, light scattering will decrease and so will the opacity and light transmission through the material. Optimum RI matching and careful design of the DCs may produce DC materials with considerably improved optical properties. The only alternative way to obtain a highly translucent cement is to have well dispersed nano-sized particles where the dimensions of the particles are smaller than the wavelength of the visible light. Such fine scale powder particles are particularly difficult to manufacture as they have a high tendency to aggregate once mixed essentially forming larger clusters to reduce their high surface energy. Furthermore, it is difficult and costly to produce such nano particles particularly from melt-derived glasses. It is notable that translucent glass-ceramics are also produced by matching the RI between the different components in these multiphasic materials i.e. crystal phase/s and the residual "glassy" phase.

In the case of fluoride free glasses the RI of the glass can be calculated within about 0.01 by the means of Appen factors [3], which are empirically derived factors calculated on the basis 
of previous measurements of Rls of oxide glasses. Appen factors have been successfully used to calculate not only $\mathrm{RI}$ but also thermal expansion coefficients [4]. The $\mathrm{RI}$ of an oxide glass can be calculated using the following equation:

$$
n_{d}=\frac{\sum^{n}{ }_{i=1} n_{d, i} c_{i}}{100}
$$

Where $n_{d, i}$ is the Appen factor (Table 1) for the respective oxide component and $C_{i}$ is the mol $\%$ of the oxide component.

However, Appen factors for the metal fluorides are not available. Consequently, the refractive index of fluoride-containing glasses cannot be readily predicted. Fluoride components are known to reduce the $\mathrm{RI}$ of various glasses [5] and fluoride-containing glasses are attractive components for dental composites and particularly for GICs. The anticariogenic effects of fluoride have been long known [6]. Based on Scanning Electron Microradiography (SMR) in vitro studies, optimum fluoride concentrations under acidic conditions have also been proposed by Mohammed et al. [7].

However, despite the importance of $\mathrm{RI}$ it has rarely been measured for fluoride containing dental glasses there is only one peer reviewed article published in the literature. This article demonstrates how increasing $\mathrm{CaF}_{2}$ content in bioactive glasses allows design of dental composite materials with improved optical properties, such as improved depth of cure and reduced light transmission [8]. Improved depth of cure of the DC will also result in increased longevity of the tooth restoration due to minimized shrinkage and increased polymerization.

The ability to model the role of metal fluorides on the $\mathrm{Rl}$ of multicomponent glasses also allows the prediction of $\mathrm{RI}$ of fluorine-containing glass-ceramics (GCs) used in restorative dentistry, particularly GCs based on fluorapatite and fluormica phases. Since translucency is 
required for aesthetics, it is important to match the $\mathrm{Rl}$ of the crystal phase to the residual glass phase. In these glass-ceramics, relatively large interlocking crystals are required to provide optimum strength and fracture toughness, as well as machinability in the case of mica glass-ceramics [9]. GCs containing nano-sized crystal phases would provide the desired aesthetics, however at the expense of mechanical properties and machinability. Therefore in summary it is necessary to develop a model by which Rls of fluoride-containing glasses can be predicted.

The objectives of this paper are to:

i) Measure the $\mathrm{RI}$ of two types of the fluoride-containing glasses used in glass (ionomer) cement formulations and as potential remineralising additives in various dental restorative materials.

ii) To develop Appen Factors for fluoride-containing glasses so that Rls of these glasses may be calculated which will allow the design of restoratives with improved translucency.

\subsection{Materials and Methods}

\subsection{Glass Synthesis}

Two series of bioactive glasses containing fluoride components were produced. These are given in Tables 2 to 3 . The bioactivity of these two series of bioactive glasses was previously studied by Mneimne et al. [10] and Lynch et al. [11] respectively. In these glasses the metal fluorides were added to the composition rather than substituted for the metal oxide. All glasses were melted in platinum/rhodium $80 / 20$ crucibles. Details of the synthesis conditions are given in the respective papers [10] and [11]. The first series of ionomer-type glasses (Table 4) are based on the series $4.5 \mathrm{SiO}_{2} 3 \mathrm{Al}_{2} \mathrm{O}_{3} 1.5 \mathrm{P}_{2} \mathrm{O}_{5}(5-\mathrm{X}) \mathrm{CaOXCaF}$. In this series of ion-leachable glasses $\mathrm{CaO}$ is substituted for $\mathrm{CaF}_{2}$ on a molar basis. These glasses were 
synthesized using a method described earlier by Stanton and Hill [12]. A second series of high fluorine ionomer-type glasses (Table 5) were provided by Cera Dynamics Limited (Stoke-on-Trent, UK). These high fluorine glass samples were produced in a custom-built cold-top furnace to prevent fluorine volatilization. Full chemical analyses of the industrially manufactured glasses was carried out by X-ray fluorescence. These glasses have much higher fluorine contents than the laboratory synthesized ionomer glasses whose compositions were designed to prevent fluorine loss as volatile silicon tetrafluoride [13].

\subsection{Measurement of RI}

Fluoride-containing glasses are prone to rapid crystallization [12] and fluoride loss on casting therefore as opposed to using Abbé refractometer refractive indices of the samples were measured by the Becke line test [14]. The refractive indices all fluoride-containing amorphous powdered glass samples were measured using polarized light microscopy by mounting the amorphous glass samples in suitable immersion liquids (Cargille, USA) and making observations of the Becke line. The immersion liquids have known refractive index values ranging from 1.45 to 1.70 with 0.01 intervals. Refractive Index measurements were performed at room temperature $\left(\sim 20^{\circ} \mathrm{C}\right)$ using the sodium $\mathrm{D}$ line. The microscope was calibrated prior to each measurement using a known RI glass sample. Digital images of the glass samples were captured using a digital camera ( $Q$ Imaging, Canada) affixed to the microscope and digitised by manufacturer's software.

\subsection{Appen factors}

First, eq. (1) was used to calculate Rls of all glass samples. Since no Appen factors are available for the metal fluorides, the metal fluoride component contribution to the RI was underestimated. To compensate for this, multiple factors were tried for the respective metal 
fluoride $\left(\mathrm{CaF}_{2} / \mathrm{SrF}_{2}\right)$ component until the calculated $\mathrm{RI}$ value matched to within 0.005 to experimentally derived $\mathrm{RI}$ value.

\subsection{Results}

All glasses used in the study were found to be amorphous by X-ray powder diffraction analyses. Figure $1(\mathrm{a}-\mathrm{C})$ shows the $\mathrm{RI}$ as a function of $\mathrm{CaF}_{2}, \mathrm{SrF}_{2}$ and $\mathrm{F}$ content for phosphosilicate bioactive glasses and alumino-silicate ionomer-type glasses. There is a linear decrease in $\mathrm{Rl}$ with metal fluoride/elemental fluorine content. A comparison of the experimental and calculated $\mathrm{Rl}$ values for Mneimne et al. [10] series of bioactive glasses shows a good correlation between the two (Figure 1(a)). However, for more complex F series of bioactive glasses containing additional oxide components it can be observed that there is a slight deviation between the experimental and calculated values with $\mathrm{Ca} / \mathrm{SrF}_{2}$ contents (Figure 1(b)). Figure 1(c) shows the RI for a series of ionomer glasses based on 4.5 $\mathrm{SiO}_{2} 3 \mathrm{Al}_{2} \mathrm{O}_{3} 1.5 \mathrm{P}_{2} \mathrm{O}_{5}(5-\mathrm{X}) \mathrm{CaOXCaF}$. The Rls calculated using Appen factors agrees well with the experimentally determined RIs. Figure $1(\mathrm{~d})$ shows the $\mathrm{RI}$ as a function of $\mathrm{F}$ content for the industrially manufactured high fluorine (PF) series (Table 4) of glasses. In summary, there is a clear linear relationship between fluoride content (either as elemental $F$ or as a metal fluoride) and refractive index of the glasses studied. Table 6 shows series-specific Appen factors derived from this study.

\subsection{Discussion}

Based on the experimentally derived Rls of the fluorine-containing glass samples, a linear $\left(R^{2}=0.98\right)$ correlation between elemental fluorine/metal fluoride content and the refractive index of glasses is clearly observed. Generally, fluorine containing glasses have larger atomic spacings and therefore more disrupted structure. Larger spacing in the glass network results in the reduction in glass density and thus is attributed to lower refractive index. It has been long known that there is a linear correlation between density and refractive index in 
glasses [15]. However, many materials other than glasses do not exhibit this phenomenon. It may not be surprising that incorporation of fluoride lowers the dielectric constant of the glasses which is observed in other dielectric materials [16] and results in reduced polarizability and henceforth a reduction in refractive index.

For the first series of bioactive glasses developed by Mneimne et al. [10] calculated and measured $\mathrm{Rl}$ values are matching within 0.005 . In this series, it was found that $\mathrm{CaF}_{2}$ contributes to the $\mathrm{RI}$ by a factor of 1.42 , which is quite close to the $\mathrm{RI}$ of crystalline $\mathrm{CaF}_{2}$, which at room temperature is 1.4338 [17]. It is notable that solid-state ${ }^{19} \mathrm{~F}$ MAS-NMR studies of related glasses by Brauer et al. [18] have shown fluorine to be present as $F-M(n)$ species where $\mathrm{M}$ is largely $\mathrm{Ca}$ with a small fraction of $\mathrm{Na}$ and $\mathrm{n}$ is close to four molecular dynamics simulations by Christie et al. [19] predict the formation of F-Ca(n) species. Thus in these glasses the fluorine exists in a fluorite like $\mathrm{F}-\mathrm{Ca}(4)$ environment and it is therefore not surprising that the $\mathrm{RI}$ can be predicted based on a model assuming the presence of a fluorite-like environment. Furthermore, Brauer et al. [20] measured the density of $\mathrm{CaF}_{2}$ containing bioactive glasses and showed the density could be predicted based on the assumption of fluorine existing in a $\mathrm{CaF}_{2}$ like environment and using a density factor for crystalline $\mathrm{CaF}_{2}$. It is worth noting that in the present glasses, as well as the ones studied by Brauer et al. [20] the $\mathrm{CaF}_{2}$ was added to the glass rather than being substituted for $\mathrm{CaO}$ and in these glasses there is no change in the non-bridging oxygen content and the $Q$ speciation of the silicon remains constant. In the original studies of Hench et al. [21] and more recently by Lusvardi et al. [22] $\mathrm{CaF}_{2}$ was substituted for $\mathrm{CaO}$ which results in changes in the nonbridging oxygen content of the glass and the silicon speciation as well as potential loss of fluorine as silicon tetrafluoride during melting.

The calculations for the second series of bioactive glasses (Table 3) [11] with strontium and potassium components have also been performed by assuming the nominal proportions of $\mathrm{CaF}_{2}$ and $\mathrm{SrF}_{2}$ incorporated in the original glass composition. It was found that metal 
fluorides contribute to the $\mathrm{RI}$ by a factor of $1.45\left(\mathrm{CaF}_{2}\right)$ and $1.47\left(\mathrm{SrF}_{2}\right)$, which is higher than the factor for the first series. In the final melted glass composition the fluorine might be expected to form more $\mathrm{F}-\mathrm{Ca}(\mathrm{n})$ species than $\mathrm{F}-\mathrm{Sr}(\mathrm{n})$ species since $\mathrm{Ca}^{2+}$ has a slightly smaller ionic size than $\mathrm{Sr}^{2+}$ and this might be expected to favour $\mathrm{F}-\mathrm{Ca}(\mathrm{n})$ speciation. In addition there is likely to be mixed $\mathrm{F}-\mathrm{Ca} / \mathrm{Sr}(\mathrm{n})$ and $\mathrm{F}-\mathrm{Na}(\mathrm{n})$ sites where $\mathrm{Na}$ and $\mathrm{Ca}$ is more prevalent than $\mathrm{Sr}$ and this may an effect on the $\mathrm{RI}$ and hence may explain why the Appen factor for the metal fluoride component in this series is higher.

Appen factor for $\mathrm{CaF}_{2}$ for the first series of aluminosilicate glasses (Table 4) was found to be 1.59 , which is much higher when compared to the $\mathrm{RI}$ of crystalline $\mathrm{CaF}_{2}$. In addition, it was also found that Appen factor for $\mathrm{P}_{2} \mathrm{O}_{5}$ is different from that published by Appen [3] and is around 1.48 for this series of glasses. This may be due to different phosphorus speciation in glass compositions containing aluminium and can be linked to several structural aspects [23].

Characterization by ${ }^{19} \mathrm{~F},{ }^{31} \mathrm{P},{ }^{29} \mathrm{Si}$ and ${ }^{27} \mathrm{Al}$ MAS-NMR [24] indicate that the structure of ionomer type glasses is much more complex than the fluoride containing bioactive glasses. The fluorine can exist as Al-F-Ca(n), as well as $\mathrm{F}-\mathrm{Ca}(\mathrm{n})$ and the proportion of these two species changes with the glass composition [24]. The assumption of the glass consisting of a $\mathrm{CaF}_{2}$ free glass plus $\mathrm{CaF}_{2}$ like species in the calculation of the $\mathrm{RI}$ is only partially valid and neglects the presence of $\mathrm{Al}-\mathrm{F}-\mathrm{Ca}(\mathrm{n})$ species. In addition substituting $\mathrm{CaF}_{2}$ for $\mathrm{CaO}$ may also reduce the non-bridging oxygen content of the glass, which will also influence the RI. In addition increasing fluorine content can cause the $\mathrm{Al}$ to move from $\mathrm{Al}(\mathrm{IV})$ to higher coordination states of $\mathrm{V}$ and $\mathrm{VI}$.

Due to the complexity of the second series of high-fluorine ionomer-type glasses (Table 5) the data is expressed as measured $\mathrm{RI}$ as a function of elemental fluorine content. These compositions contain excessive amounts of fluorine and further structural characterization is 
ongoing. However, Rls that all within the compositional domain of this series of glasses can also be predicted based on the amount of elemental fluorine in mol\% using equation for straight line expressed in Figure 1(d).

Most commercial ionomer glasses also contain small amounts of sodium whereby it forms $\mathrm{Al}-\mathrm{F}-\mathrm{Na}(\mathrm{n})$ species in the glass in addition to $\mathrm{Al}-\mathrm{F}-\mathrm{Ca}(\mathrm{n})$ and $\mathrm{F}-\mathrm{Ca}(\mathrm{n})$ species. Furthermore, many commercial glasses also contain strontium [23], which will result in Al-F-Sr(n) and F$\operatorname{Sr}(\mathrm{n})$ speciation in addition to mixed species if calcium is included in the composition. In general the amount of sodium in ionomer glass compositions is typically less than $1 \%$ so the formation of $\mathrm{Al}-\mathrm{F}-\mathrm{Na}(\mathrm{n})$ species is not likely to have a large influence on the $\mathrm{RI}$ of ionomertype glasses.

In regard to glass ionomer cements it is necessary that the $\mathrm{RI}$ of glass matches the $\mathrm{RI}$ of the polysalt matrix. This can be quite well facilitated in cement compositions where the initial difference between refractive index of the glass and the refractive index of the polyacid solution is lower.

\subsection{Conclusions}

The RI of fluoride containing bioactive glasses correlates linearly with metal fluoride content and the RI can also be predicted readily using Appen factors close to that of fluoride containing crystalline phases, such as $\mathrm{CaF}_{2}$ as proposed in the study. The Rls of the more complex ionomer glasses also demonstrate a linear relationship with fluoride content. Nonetheless, the paper proposes a modified Appen Model with new composition-specific Appen factors for the metal fluorides for the development of highly translucent dental materials and improved depth of cure of dental composites. The present study also provides 
a very useful tool for the design of highly advanced restorative materials which can exhibit bioactivity alongside improved aesthetics and increased restoration longevity.

\section{Acknowledgements}

The authors would like to thank Cera Dynamics Limited, part of the James Kent Group and the Institute of Dentistry (Queen Mary University of London) for funding this project. The authors would also like to thank Dr Philip Frampton (Cera Dynamics Limited) for the high fluorine samples and XRF analyses. And finally, the corresponding author would also like to thank Dr Jamila Almohamadi (Queen Mary University of London) for her explanation of the Becke line technique. 


\section{References}

[1] Shortall, A, Palin W, and Burtscher P. Refractive index mismatch and monomer reactivity influence composite curing depth. Journal of Dental Research 2008;87;84-88.

[2] Hadis MA, Tomlins PH, Shortall AC, Palin WM. Dynamic monitoring of refractive index change through photoactive resins. Dental Materials 2010;26(11):1106-1112.

[3] Appen, A. A. Khimiia stekla. Khimiia. Leningrad, Leningradskoe Otdnie: 1974;310-310.

[4] O'Donnell M, Watts S, Law R. and Hill RG. Effect of $\mathrm{P}_{2} \mathrm{O}_{5}$ content in two series of soda lime phosphosilicate glasses on structure and properties - Part II: Physical properties Journal of Non-Crystalline Solids 2008;354:3561-3566.

[5] Gan F. Optical properties of fluoride glasses - a review. Journal of NonCrystalline Solids 1995; 184:9-20.

[6] Featherstone J. Prevention and reversal of dental caries: Role of low level fluoride. Community Dentistry and Oral Epidemiology 1999;27(1):31-40.

[7] Mohammed N, Lynch R. and Anderson P. Effects of fluoride concentration on enamel demineralization kinetics in vitro. Journal of Dentistry 2014;42(5):613-618.

[8] Hadis MA, Choong N, Morrell A, Martin RA, Shelton RM, Palin WM. Decreasing glass refractive index for development of light-curable bioactive composites. Dental Materials 2016;32S:e21-e22

[9] Höland W, and Beall GH. Glass-ceramic technology. Hoboken, New Jersey Westerville, Ohio, Wiley ;The American Ceramic Society; 2012

[10] Mneimne M, Hill RG, Bushby AJ and Brauer DS. High phosphate content significantly increases apatite formation of fluoride-containing bioactive glasses. Acta Biomater 2011;7(4):1827-1834.

[11] Lynch E, Brauer D, Karpukhina N, Gillam D and Hill R. Multi-component bioactive glasses of varying fluoride content for treating dentin hypersensitivity. Dental Materials 2012;28(2):168-178.

[12] Stanton $\mathrm{K}$. and Hill R. The role of fluorine in the devitrification of $\mathrm{SiO}_{2} \cdot \mathrm{Al}_{2} \mathrm{O}_{3} \cdot \mathrm{P}_{2} \mathrm{O}_{5} \cdot \mathrm{CaO} \cdot \mathrm{CaF}_{2}$ glasses. Journal of Materials Science 2000;35(8):1911-1916.

[13] Hill R, Wood D. and Thomas M. Trimethylsilylation analysis of the silicate structure of fluoro-alumino-silicate glasses and the structural role of fluorine. Journal of Materials Science 1999;34(8):1767-1774. 
[14] Saylor CP. Accuracy of microscopical methods for determining refractive index by immersion. Journal of Research 1995;15(3):17.

[15] Bannister F. A. A, relation between the density and refractive index of silicate glasses, with application to the determination of imitation gemstones, Mineral Magazine. 1931;22:136-154.

[16] Yang P, Yuan M, Zeigler D, Watkins S, Lee J, and C. Luscombe C. Influence of fluorine substituents on the film dielectric constant and open-circuit voltage in organic photovoltaics. Journal of Materials Chemistry C 2014;2(17):3278-3284.

[17] Malitson IH. A Redetermination of Some Optical Properties of Calcium Fluoride. Applied Optics 1963;2(11):1103-1107.

[18] Brauer D, Karpukhina N, Law R, and Hill R. Structure of fluoride-containing bioactive glasses. Journal of Materials Chemistry 2009;19(31): 5629-5636.

[19] Christie J, Pedone A, Menziani M and Tilocca A. Fluorine Environment in Bioactive Glasses: ab Initio Molecular Dynamics Simulations. Journal of Physical Chemistry B 2011;115(9):2038-2045.

[20] Brauer D, Al-Noaman A, Hill R. and Doweidar H. (2011). Density-structure correlations in fluoride-containing bioactive glasses. Materials Chemistry and Physics 2011;130(1-2): 121-125.

[21] Hench LL., D. Spilman DB and Hench JW. Fluoride-containing Bioglass ${ }^{\mathrm{TM}}$ compositions, Google Patents 1998.

[22] Lusvardi G, Malavasi G, Cortada M, Menabue L, Menziani M, Pedone A and Segre $U$. Elucidation of the structural role of fluorine in potentially bioactive glasses by experimental and computational investigation. Journal of Physical Chemistry B 2008;112(40):12730-12739.

[23] Stamboulis A, Law R. and Hill R. (2004). Characterisation of commercial ionomer glasses using magic angle nuclear magnetic resonance (MAS-NMR). Biomaterials 2004;25(17):3907-3913.

[24] Zainuddin N, Karpukhina N, Law R. and Hill R. Characterisation of a remineralising Glass Carbomer ${ }^{\circledR}$ ionomer cement by MAS-NMR Spectroscopy. Dental Materials 2012;28(10):1051-1058. 
Tables

Table 1: Appen factors for various oxides [3]

\begin{tabular}{ll}
\hline Oxide & $\begin{array}{l}\text { Appen } \\
\text { Factor }\end{array}$ \\
\hline $\mathrm{SiO}_{2}$ & 1.4585 \\
$\mathrm{Al}_{2} \mathrm{O}_{3}$ & 1.52 \\
$\mathrm{P}_{2} \mathrm{O}_{5}$ & 1.31 \\
$\mathrm{Na}_{2} \mathrm{O}$ & 1.575 \\
$\mathrm{ZnO}$ & 1.71 \\
$\mathrm{~K}_{2} \mathrm{O}$ & 1.575 \\
$\mathrm{CaO}$ & 1.73 \\
$\mathrm{SrO}$ & 1.775 \\
\hline
\end{tabular}

Table 2: Compositions of laboratory bioactive alkali phospho-silicate glasses (mol \%) [10]

\begin{tabular}{llllll}
\hline & $\mathrm{SiO}_{2}$ & $\mathbf{P}_{2} \mathrm{O}_{5}$ & $\mathrm{CaO}$ & $\mathrm{CaF}_{2}$ & $\mathrm{Na}_{2} \mathrm{O}$ \\
\hline B2 & 36.41 & 6.04 & 24.74 & 4.53 & 28.28 \\
$\mathbf{C 2}$ & 34.60 & 5.74 & 23.51 & 9.28 & 26.87 \\
D2 & 32.95 & 5.47 & 22.38 & 13.62 & 25.59 \\
E2 & 31.37 & 5.21 & 21.31 & 17.76 & 24.36 \\
F2 & 28.40 & 4.71 & 19.29 & 25.54 & 22.06 \\
\hline
\end{tabular}

Table 3: Compositions of multicomponent bioactive glasses in mol\% [11]

\begin{tabular}{lllllllllll}
\hline & $\mathrm{SiO}_{2}$ & $\mathrm{P}_{2} \mathrm{O}_{5}$ & $\mathrm{CaO}$ & $\mathrm{CaF}_{2}$ & $\mathrm{SrO}$ & $\mathrm{SrF}_{2}$ & $\mathrm{Na}_{2} \mathrm{O}$ & $\mathrm{K}_{2} \mathrm{O}$ & $\mathrm{ZnO}$ & $\mathrm{CaF}_{2}+\mathrm{SrF}_{2}$ \\
\hline F0 & 44 & 5 & 15 & 0 & 15 & 0 & 10 & 10 & 1 & 0 \\
F4 & 41.91 & 4.76 & 14.29 & 2.38 & 14.29 & 2.38 & 9.53 & 9.53 & 0.95 & 4.76 \\
F13 & 38.01 & 4.32 & 12.96 & 6.81 & 12.96 & 6.81 & 8.64 & 8.64 & 0.86 & 13.62 \\
F17 & 36.19 & 4.11 & 12.34 & 8.88 & 12.34 & 8.88 & 8.22 & 8.22 & 0.82 & 17.76 \\
F25 & 32.76 & 3.72 & 11.17 & 12.77 & 11.17 & 12.77 & 7.45 & 7.45 & 0.74 & 25.54 \\
F32 & 29.61 & 3.36 & 10.09 & 16.36 & 10.09 & 16.36 & 6.73 & 6.73 & 0.67 & 32.72 \\
\hline
\end{tabular}


Table 4: Compositions of model laboratory ionomer-type glasses in mol \%

\begin{tabular}{llllll}
\hline & $\mathrm{SiO}_{2}$ & $\mathrm{Al}_{2} \mathrm{O}_{3}$ & $\mathrm{P}_{2} \mathrm{O}_{5}$ & $\mathrm{CaO}$ & $\mathrm{CaF}_{2}$ \\
\hline LG99 & 32.14 & 21.43 & 10.71 & 14.29 & 21.43 \\
LG95 & 32.14 & 21.43 & 10.71 & 20.00 & 15.71 \\
LG134 & 32.14 & 21.43 & 10.71 & 25.00 & 10.71 \\
LG115 & 32.14 & 21.43 & 10.71 & 28.57 & 7.14 \\
LG116 & 32.14 & 21.43 & 10.71 & 35.71 & 0.00 \\
\hline
\end{tabular}

Table 5: Compositions of high fluorine ionomer-type glasses produced by Cera Dynamics Limited (mol \%)

\begin{tabular}{lccccccc}
\hline & $\mathrm{SiO}_{2}$ & $\mathrm{Al}_{2} \mathrm{O}_{3}$ & $\mathrm{P}_{2} \mathrm{O}_{5}$ & $\mathrm{Na}_{2} \mathrm{O}$ & $\mathrm{CaO}$ & SrO & Fluorine \\
\hline PF124 & 20.00 & 14.47 & 1.87 & 5.15 & 0.13 & 8.47 & 49.90 \\
PF125 & 28.71 & 17.48 & 2.12 & 1.67 & 0.09 & 15.63 & 34.30 \\
PF126 & 23.35 & 13.30 & 2.05 & 5.32 & 0.12 & 8.86 & 47.00 \\
PF127 & 29.16 & 15.88 & 2.56 & 1.66 & 0.08 & 15.51 & 35.15 \\
PF128 & 25.03 & 15.90 & 7.44 & 1.67 & 23.61 & 0.46 & 25.89 \\
PF129 & 25.73 & 17.34 & 8.37 & 1.32 & 26.98 & 0.08 & 20.18 \\
PF130 & 27.85 & 18.14 & 4.34 & 1.55 & 27.80 & 0.02 & 20.30 \\
PF131 & 26.17 & 17.73 & 4.21 & 1.48 & 12.59 & 16.01 & 21.81 \\
\hline
\end{tabular}

Table 6: Empirically derived Appen factors

\begin{tabular}{llll}
\hline & $\mathrm{CaF}_{2}$ & $\mathrm{SrF}_{2}$ & $\mathbf{P}_{2} \mathbf{O}_{5}$ \\
\hline$[8]$ & 1.42 & - & - \\
[9] & 1.45 & 1.47 & - \\
LG & 1.59 & - & 1.48 \\
\hline
\end{tabular}

